\title{
The Association Between Child and Family Characteristics and the Mental Health and Wellbeing of Caregivers of Children with Autism in Mid-Childhood
}

\author{
Erica Salomone ${ }^{1,2}$ (1) Kathy Leadbitter ${ }^{3} \cdot$ Catherine Aldred $^{3} \cdot$ Barbara Barrett $^{2} \cdot$ Sarah Byford $^{2} \cdot$ Tony Charman $^{2}$. \\ Patricia Howlin ${ }^{2}$. Jonathan Green ${ }^{3,4,5} \cdot$ Ann Le Couteur ${ }^{6,7} \cdot$ Helen McConachie $^{6} \cdot$ Jeremy R. Parr ${ }^{6}$. Andrew Pickles ${ }^{2}$. \\ Vicky Slonims ${ }^{8} \cdot$ The PACT Consortium
}

Published online: 25 November 2017

(c) The Author(s) 2017. This article is an open access publication

\begin{abstract}
We examined predictors of mental health difficulties and wellbeing in caregivers of children with autism in the Pre-school Autism Communication Trial cohort in middle childhood $(\mathrm{N}=104)$. Child's intellectual disability, daily living skills impairment, elevated emotional and behavioural difficulties, high educational level of caregiver and household income below the median significantly predicted caregivers' mental health difficulties, but autism severity, child communication skills and family circumstances did not. Lower caregiver mental wellbeing was predicted by elevated child emotional and behavioural difficulties. The need to support the mental health and wellbeing of caregivers of children with autism is discussed in light of the results.
\end{abstract}

Keywords Autism $\cdot$ Mental health $\cdot$ Mental wellbeing $\cdot$ Caregiver $\cdot$ Daily living skills $\cdot$ Emotional and behavioural difficulties

Collaborators of The PACT Consortium are listed in

"Acknowledgments".

Erica Salomone

erica.salomone@unito.it

University of Turin, Via Po, 14, 10123 Turin, Italy

2 Institute of Psychiatry, Psychology \& Neuroscience, King's College London, London, UK

3 University of Manchester, Manchester, UK

4 UK Royal Manchester Children's Hospital, Manchester Academic Health Sciences Centre, Manchester, UK

5 Greater Manchester Mental Health NHS Foundation Trust, Manchester, UK

6 Newcastle University, Newcastle, UK

7 Northumberland, Tyne and Wear NHS Foundation Trust, Newcastle upon Tyne, UK

8 Evelina London Children's Hospital, Guys and St Thomas University NHS Trust, London, UK

\section{Introduction}

Among parents of children with autism, higher rates of mental health problems and stress are reported compared to parents of children with other developmental or physical disabilities (Olsson and Hwang 2001; Cohrs and Leslie 2017; Hayes and Watson 2013; Abbeduto et al. 2004). Such increased rates have been termed as the 'ASD disadvantage', to indicate that poorer mental health in the caregiver may be directly related to the child's diagnostic features (Hartley et al. 2012). There are indeed several characteristics of children with autism that can exacerbate parenting difficulties, increase stress and reduce wellbeing. These include 'core' autism symptoms (e.g. social communication impairments, interfering restrictive/repetitive behaviours), but also poor cognitive and adaptive skills, and the emotional and behavioural difficulties that are frequently co-occurring features. However, research investigating the association between child autism severity and the mental health of caregivers has yielded mixed results. Thus, although some studies (Benson 2006; Hastings and Johnson 2001; Schieve et al. 2011) report a positive association with stress, others do not (McStay et al. 2014; Hastings et al. 2005). Similarly, 
while impairments in adaptive behaviour, and specifically daily living skills (DLS), are key areas of deficit in autism, some studies have reported a relationship between better DLS and lower parenting stress (Tomanik et al. 2004; Green and Carter 2014) and others have found no association (Lecavalier et al. 2006; Estes et al. 2009, 2013; PetersScheffer et al. 2012). For overall adaptive behaviour, both a negative association (Hall and Graff 2011) and lack of association (Feldman et al. 2007) with parental stress have been described. Cognitive impairment frequently co-occurs in autism (CDC 2014), but the association of child cognitive functioning with parental outcomes is not fully understood. Poorer parental outcomes have been reported to be associated with both intellectual disability (ID) (Baker-Ericzén et al. 2005) and higher intellectual functioning (Rivard et al. 2014), while other studies did not report any association (Peters-Scheffer et al. 2012; Estes et al. 2013). In contrast, data on the association between higher rates of child emotional and behavioural problems and poorer parental psychological well-being are more consistent (Estes et al. 2013; Lecavalier et al. 2006; Peters-Scheffer et al. 2012; Hartley et al. 2012). Among family factors, social support including support from a partner (Ekas et al. 2010; Dunn et al. 2001; Bromley et al. 2004) may act as buffers or protective factors. In contrast, family disadvantage, such as parenting multiple children with disabilities (Orsmond et al. 2007) and being a single parent (Olsson and Hwang 2001) may exacerbate stress and mental health difficulties. With regard to socioeconomic factors, lower parental education and income have been found, in some cases, to be associated with higher rates of common mental health difficulties and poorer psychological wellbeing in a general population sample (Jones and Nicolás 2004). Finally, child's age may be a moderating factor in the relationship between child and family characteristics and parental psychological outcomes. Thus, there is some evidence that the maturational changes that occur in middle childhood combined with children's increased exposure to social situations require major adjustments in parental expectations which, in turn, may be associated with higher risk for stress compared to both early years and adolescence (Orr et al. 1993).

In summary, while there is substantial evidence of a relationship between child and family characteristics and parental psychological outcomes, the interpretation of apparent discrepancies in the findings is made difficult by the fact that such factors are often examined in isolation, and not within more comprehensive models. Additionally, the outcomes considered include a range of constructs, from mental health difficulties, to stress and reduced mental wellbeing. This methodological issue reflects a broader conceptual problem in measuring psychological outcomes, that is, the question of the degree of overlap between the absence of mental health symptoms and good psychological well-being.
These constructs are often correlated but have evidence of distinct antecedents (Kinderman et al. 2015).

In light of these considerations, this study focuses on mental health difficulties and mental wellbeing in caregivers of children with autism in mid-childhood, examining the association of both with a range of child and family factors. The study is a secondary analysis of data from the follow-up to the Pre-school Autism Communication Trial (PACT) (Pickles et al. 2016). PACT was a two-arm single-blind randomised controlled trial comparing a parent-mediated, communication focussed intervention with treatment as usual; at the original recruitment, children were between 2 and 4 years 11 months and met criteria for 'core autism' (Green et al. 2010). Here we examine rates of mental health difficulties and mental wellbeing in the parents at the 6-year follow-up. We explore the relationship with child factors (autism severity, language, intellectual disability (ID), daily living skills, emotional and behavioural difficulties) and family factors (income, level of education, being a single parent, parenting multiple children with developmental difficulties, PACT therapy in pre-school years). Based on the available evidence, we hypothesise that mental health and mental wellbeing would be lower in caregivers of children with elevated emotional and behavioural difficulties. In light of mixed findings for the other factors, we do not pre-specify further hypotheses.

\section{Methods}

\section{Participants}

Participants were caregivers enrolled in the PACT randomised controlled trial (Green et al. 2010). The 12-month intervention focused on modifying the parent-child interaction in order to enhance child communication (Aldred et al. 2010, PACT Intervention procedure). The PACT trial and follow-up study (Pickles et al. 2016) were approved by the Central Manchester Multicentre Research Ethics Committee (Manchester, UK); further information on the studies is available online (http://research.bmh.manchester.ac.uk/pact/about). The current analysis is based on those caregivers who completed measures of mental health and mental wellbeing (see "Measures") at the follow-up ascertainment when their children were aged 8-12 years. None of these parents had been identified as having severe psychiatric illness when the child was aged 2-4 years since this was an exclusion criterion for the trial. The total number of caregivers was 104 ( $86 \%$ of those seen at the followup; $68 \%$ of the original cohort); of these $49(47.1 \%)$ had been assigned to the treatment arm in the original trial. 
Median caregiver age was 41 years; almost all respondents were mothers $(n=96,92.3 \%) ; 60 \%(n=61)$ were White British; 17\% ( $\mathrm{n}=17)$ Black African; 8\% $(\mathrm{n}=8)$ Asian; $15 \%(n=15)$ of other ethnic background.

\section{Measures}

\section{Mental Health}

The General Health Questionnaire-12 items (GHQ-12, Goldberg 1992) was used to measure mental health difficulties. The GHQ-12 is sensitive to short-term psychiatric conditions and focuses on the inability to carry out normal functions (e.g. 'not been able to concentrate on what you're doing') and psychological distress ('feeling unhappy or depressed'). The 'GHQ-scoring' method, or 'caseness' approach to scoring was used. Items are rated as 1 if the response is 'less than usual' or 'much less than usual' (and rated as 0 otherwise), producing a possible Total score ranging from 0 to 12 . As recommended in the WHO study (Goldberg et al. 1997), the screening cut-off was set at $\geq 2$ on the Total score to define presence of mental health difficulties, or 'caseness for mental health difficulties' (hereafter, 'GHQ-12 caseness', as is general in the literature). As per guidelines, missing items were recoded as zero scores (there was 1 missing item for 1 participant).

\section{Mental Wellbeing}

The Warwick-Edinburgh Mental Wellbeing Scale questionnaire (WEMWBS, Tennant et al. 2007) was used to measure mental wellbeing. The 14 items, rated from 1 ('none of the time') to 5 ('all of the time'), are positively worded, represent positive attributes of wellbeing and cover both feeling (e.g., 'I've been feeling confident') and functioning (e.g., 'I've been dealing with problems well'). Following the authors' recommendation, the Total wellbeing score, calculated as the sum of the ratings on each of the 14 items, was prorated for 7 participants (each of whom had 1 missing item).

\section{Child Factors}

Autism severity was assessed with the Autism Diagnostic Observation Schedule Second Edition (ADOS-2, Lord et al. 2012). The ADOS-2 Calibrated Severity Scores (CSS) for Social Affect (SA) and Restricted and Repetitive Behaviours (RRB) were computed and provide standardised ASD severity for the two domains based on the Module administered and the participant's age and verbal ability (Hus et al. 2014). Participants were classified by level of speech as per the ADOS-2 Module administered, producing four categories of level of speech: Module 1 no words/Module 1 some words/
Module 2 phrase speech/Module 3 fluent speech. Cognitive functioning and adaptive behaviour were respectively assessed with the British Ability Scales Third Edition (BAS3, Elliott and Smith 2011) and the Vineland Adaptive Behavior Scales II Daily Living Skills (DLS) domain (VABS II, Sparrow 2005). Emotional and behavioural difficulties were measured by parent report using the Strengths and Difficulties Questionnaire (SDQ; Goodman 1997), a 25-item scale comprised of hyperactivity, emotional symptoms, conduct problems and peer problems subscales (as well as prosocial). Scale scores can be prorated if at least three items in each subscale are completed and UK normed screening cut-offs are available to identify 'abnormal' (top 10\%) and 'borderline' (the next 10\%) levels of difficulties by age and gender (http://www.sdqinfo.com). Given the expected elevated rates of emotional and behavioural difficulties on the SDQ in school-age children with ASD (Salomone et al. 2014), the 'borderline' and 'typical' categories were collapsed for the purposes of this analysis.

\section{Family Factors}

Household income was collected for both carers, where applicable, if they were sharing income (even if they were not living together). Participants indicated the category most appropriate for their income (ranging from $<£ 5000$ to $>£ 100,000$ ). A 'household income' value was calculated by taking the middle point of each income category and summing across both carers where applicable. The median household disposable income reported by the UK National Office for Statistics (ONS) for the financial year ending 2015 ( $£ 25,700$; ONS 2016) was used to create a dummy variable for household income (below/equal and above the median). Caregivers indicated their educational level on the 8-level UK National Qualifications Framework (NQF). The number of people living in the house and the presence of developmental difficulties or disorder in siblings of the target child were recorded; caregivers self-identified ethnicity.

\section{Data Analysis}

To investigate the association of child and parental characteristics with caregiver mental health difficulties and mental wellbeing, we conducted a multiple logistic regression and a multiple linear regression with, respectively, GHQ-12 'caseness' (i.e., above GHQ-12 cut off for mental health difficulties) and WEMWBS Total score as dependent variables. Odds ratios (OR) and 95\% confidence intervals (CIs) are presented for the logistic regression, and the unstandardized and standardized coefficients for the multiple linear regression. 
Variables for child's functioning (cognitive level [BAS Standard Nonverbal Composite (SNC)]; daily living impairment [VABS DLS Standard Score (SS)]; emotional and behavioural difficulties [SDQ Total problems]) and socioeconomic factors (income and educational level) were dichotomised into clinically meaningful subgroups in order to better capture their significance, as well as to facilitate the interpretation of the parameters (Ragland 1992).

The predictors in each model were child's age (years), social affect (ADOS-2 SA CSS), restrictive and repetitive behaviours (ADOS-2 RRB CSS), level of speech (Module 1 no words/Module 1 some words/Module 2 phrase speech/ Module 3 fluent speech), presence of intellectual disability (ID; BAS SNC $\leq 70$ ), presence of DLS impairment (VABS
DLS $\leq 70$ ), presence of elevated emotional and behavioural difficulties (SDQ Total problems score 'abnormal'), parental age (years), low educational level ( $\mathrm{NQF} \leq 4)$, low household income (below median), being a single parent, presence of other children with developmental disorders, PACT therapy in pre-school years.

\section{Results}

\section{Child and Family Characteristics}

Table 1 presents a summary of child and caregiver characteristics and Table 2 provides rates of GHQ- 12 'caseness' and WEMWBS scores by each factor.
Table 1 Participants' characteristics

\begin{tabular}{|c|c|c|c|c|}
\hline & $\mathrm{N}$ & $\mathrm{n}(\%)$ & $\mathrm{M}(\mathrm{SD})$ & Range \\
\hline \multicolumn{5}{|l|}{ Child characteristics } \\
\hline Age (years) & 104 & & $10.55(0.79)$ & $8.17-12.67$ \\
\hline Males & 104 & $94(90.4 \%)$ & & \\
\hline Autism severity (ADOS-2) & 99 & & & \\
\hline Total (CSS) & & & $6.62(1.84)$ & $1-9$ \\
\hline Social affect (SA CSS) & & & $7.18(1.98)$ & $1-10$ \\
\hline Restrictive and repetitive behaviours (RRB CSS) & & & $8.26(1.69)$ & $1-10$ \\
\hline Level of speech (ADOS-2 module administered) & 99 & & & \\
\hline Module 1 few/no words & & $25(25.3 \%)$ & & \\
\hline Module 1 some words & & $12(12.1 \%)$ & & \\
\hline Module 2 phrase speech & & $17(17.2 \%)$ & & \\
\hline Module 3 fluent speech & & $45(45.5 \%)$ & & \\
\hline Cognitive ability (BAS SNC SS) & 101 & & $66.05(22.86)$ & $40-124$ \\
\hline Adaptive behaviour & 98 & & & \\
\hline Socialization skills (VABS SOC SS) & & & $58.63(13.82)$ & $42-112$ \\
\hline Communication skills (VABS COMM SS) & & & $63.86(15.86)$ & $38-120$ \\
\hline Daily living skills (VABS DLS SS) & & & $64.33(13.83)$ & $40-112$ \\
\hline Emotional and behavioural difficulties (SDQ Total) & 89 & & $18.53(5.42)$ & $5-35$ \\
\hline \multicolumn{5}{|l|}{ Family characteristics } \\
\hline Age (years) & 88 & & $41(6.39)$ & $28-60$ \\
\hline Ethnicity & 101 & & & \\
\hline White British & & $61(60.4 \%)$ & & \\
\hline Black African & & $17(16.8 \%)$ & & \\
\hline Asian & & $8(7.9 \%)$ & & \\
\hline Other ethnic background & & $15(14.8 \%)$ & & \\
\hline Low educational level $(\mathrm{NQF} \leq 4)$ & 94 & $54(57.4 \%)$ & & \\
\hline Household income below median $(<£ 25,700)$ & 102 & $57(55.9 \%)$ & & \\
\hline Single parent & 97 & $23(23.7 \%)$ & & \\
\hline Other children with dev. diff./dis. in the house & 97 & $30(30.9 \%)$ & & \\
\hline
\end{tabular}

ADOS-2 CSS, SA CSS and RRB CSS Autism Diagnostic Observation Schedule Second Edition Composite Severity Score for Total, Social Affect and Restrictive and Repetitive Behaviours, BAS SNC SS British Ability Scales Standard Nonverbal Composite Standard Score, VABS SOC SS, VABS COMM SS and VABS $D L S$ SS Vineland Adaptive Behavior Scales Second Edition Standard Score for the Socialization, Communication and Daily Living Skills Domains, SDQ Total Strengths and Difficulties Questionnaire Total Problems Score, $N Q F$ National Qualifications Framework, dev. diff/dis. developmental difficulties/disorder 
Table 2 Rates of mental health difficulties (GHQ-12

'caseness') and wellbeing levels (WEMWBS Total) by child and family characteristics

\begin{tabular}{|c|c|c|c|c|c|c|}
\hline & \multirow[t]{2}{*}{$\mathrm{N}=104$} & \multirow[t]{2}{*}{$\mathrm{N}$} & \multicolumn{2}{|c|}{$\begin{array}{l}\text { GHQ-12 case- } \\
\text { ness }\end{array}$} & \multicolumn{2}{|c|}{ WEMWBS total } \\
\hline & & & $\mathrm{n}$ & $\%$ & $\mathrm{M}$ & SD \\
\hline \multicolumn{7}{|l|}{ Child characteristics } \\
\hline \multicolumn{7}{|l|}{ Social affect } \\
\hline ADOS-2 SA CSS high & & 49 & 23 & 46.9 & 46.73 & 10.30 \\
\hline ADOS-2 SA CSS minimal/low/moderate & & 50 & 25 & 50 & 46.73 & 8.19 \\
\hline \multicolumn{7}{|l|}{ Restrictive and repetitive behaviours } \\
\hline ADOS-2 RRB CSS high & & 70 & 35 & 50 & 46.80 & 9.24 \\
\hline ADOS-2 RRB CSS minimal/low/moderate & & 29 & 13 & 44.8 & 46.57 & 9.41 \\
\hline \multicolumn{7}{|l|}{ Level of speech } \\
\hline Module 1 few/no words & & 25 & 11 & 44 & 47.17 & 9.85 \\
\hline Module 1 some words & & 12 & 6 & 50 & 42.68 & 9.29 \\
\hline Module 2 phrase speech & & 17 & 10 & 58.8 & 43.72 & 10.89 \\
\hline Module 3 fluent speech & & 45 & 21 & 46.7 & 48.70 & 7.79 \\
\hline \multicolumn{7}{|l|}{ Cognitive ability } \\
\hline $\mathrm{BAS} \leq 70$ & & 65 & 36 & 55.4 & 45.95 & 9.87 \\
\hline $\mathrm{BAS} \geq 71$ & & 36 & 14 & 38.9 & 47.88 & 7.76 \\
\hline \multicolumn{7}{|l|}{ Daily living skills } \\
\hline VABS DLS $\leq 70$ & & 70 & 38 & 54.3 & 45.24 & 9.42 \\
\hline VABS DLS $\geq 71$ & & 28 & 9 & 32.1 & 49.80 & 7.67 \\
\hline \multicolumn{7}{|l|}{ Emotional and behavioural difficulties } \\
\hline SDQ total abnormal & & 52 & 31 & 59.6 & 44.53 & 9.03 \\
\hline SDQ total typical/borderline & & 37 & 12 & 32.4 & 49.42 & 7.61 \\
\hline \multicolumn{7}{|l|}{ Family characteristics } \\
\hline \multicolumn{7}{|l|}{ Household income } \\
\hline Below median & & 57 & 29 & 50.9 & 45.07 & 9.79 \\
\hline Above median & & 45 & 19 & 42.2 & 48.91 & 7.97 \\
\hline \multicolumn{7}{|l|}{ Educational level } \\
\hline Low $(\mathrm{NQF} \leq 4)$ & & 54 & 24 & 44.4 & 47.03 & 9.51 \\
\hline Intermediate/high $(\mathrm{NQF} \geq 5)$ & & 40 & 20 & 50 & 45.99 & 8.42 \\
\hline \multicolumn{7}{|l|}{ No. of parents living in the house } \\
\hline 1 parent & & 23 & 12 & 52.2 & 44.14 & 8.49 \\
\hline 2 parents & & 74 & 34 & 45.9 & 47.20 & 9.21 \\
\hline \multicolumn{7}{|l|}{ Other children with dev. diff./dis. } \\
\hline$\geq 1$ child & & 30 & 12 & 40 & 47.00 & 9.66 \\
\hline None & & 67 & 34 & 50.7 & 46.24 & 8.89 \\
\hline \multicolumn{7}{|l|}{ PACT therapy in pre-school years } \\
\hline No & & 55 & 30 & 54.5 & 46.56 & 9.51 \\
\hline Yes & & 49 & 20 & 40.8 & 46.81 & 8.77 \\
\hline
\end{tabular}

ADOS-2 CSS, SA CSS and RRB CSS Autism Diagnostic Observation Schedule Second Edition Composite Severity Score for Total, Social Affect and Restrictive and Repetitive Behaviours, BAS SNC SS British Ability Scales Standard Nonverbal Composite Standard Score, VABS SOC SS, VABS COMM SS and VABS DLS SS Vineland Adaptive Behavior Scales Second Edition Standard Score for the Socialization, Communication and Daily Living Skills Domains, SDQ Total Strengths and Difficulties Questionnaire Total Problems Score, $N Q F$ National Qualifications Framework, dev. diff/dis. developmental difficulties/disorder, PACT Pre-school Autism Communication Trial

\section{Mental Health Difficulties and Mental Wellbeing}

A total of 50 parents (48\%) met criteria for GHQ-12 'caseness'. A Wilcoxon signed-rank test indicated that the median mental wellbeing level of the sample $(\mathrm{Mdn}=45$, min: 25, max: 66) was lower than the median of the general UK population for the $35-44$ age range $(\mathrm{Mdn}=51$, $\mathrm{Z}=-4.344, p<.001)$. There was a strong negative 
correlation between the GHQ-12 Total score and the WEMBS Total score (Spearman's rho $=-0.65, p<.001$ ) as in the general population validation study (Spearman's rho $=-0.53$; Tennant et al. 2007). Caregivers who met GHQ-12 criteria for 'caseness' $(M=41.81, S D=7.95)$ reported significantly lower mental wellbeing levels than caregivers who fell below the GHQ-12 cut-off $(\mathrm{M}=51.18$, $\mathrm{SD}=7.77 ; \mathrm{t}(92)=-6.08, p<.001$, Cohen's $\mathrm{d}=1.19)$.

Table 3 presents the results of the multiple logistic and multiple linear regressions. The logistic regression model's $\chi^{2}$ and Hosmer and Lemeshow goodness-of-fit test statistics were respectively significant $\left(\chi^{2}=31.187, p=.008\right)$ and not significant $\left(\chi^{2}=4.384, p=.821\right)$, both indicating a well-fitting model; the Nagelkerke's $R^{2}$ was moderate (0.459). Among child characteristics, ID, DLS impairment and abnormal-range SDQ Total score significantly predicted parent mental health difficulties [respectively: $\mathrm{OR}=4.71$, $p=.047,95 \% \mathrm{CI}=(1.02,21.77) ; \mathrm{OR}=12.03, p=.015 ; 95 \%$ $\mathrm{CI}=(1.61,90.07)$ and $\mathrm{OR}=4.20, p=.041 ; 95 \% \mathrm{CI}=(1.06$, 16.68)] over and above the effect of the other variables. Taking into account the effect of all other variables, parents who reported a household income below the population median were more likely to meet 'caseness' on the GHQ-12, as were parents with a relatively higher education level [respectively: $\mathrm{OR}=16.16, p=.005,95 \% \mathrm{CI}=(1.57,166.20)$; and $\mathrm{OR}=0.07, p=.005 ; 95 \% \mathrm{CI}=(0.01,0.45)]$. There was no association between GHQ-12 'caseness' and the remaining variables. WEMWBS Total was predicted by elevated child emotional and behavioural difficulties $(\beta=-0.31, p=.011)$ alone. The overall model fit was $R^{2}=0.246$ (Table 3).

\section{Discussion}

We examined predictors of mental health difficulties and mental wellbeing in a sample of caregivers of children with autism aged 8-12 years. Measuring mental wellbeing alongside mental health difficulties is increasingly considered important for outcome evaluation from users' perspectives; however, it is unclear whether they truly represent two distinct continua. In the general population, there is evidence that mental health and mental wellbeing have different determinants, with mental health problems for instance associated with adverse life events and wellbeing more associated with social circumstances (Kinderman et al. 2015).

Table 3 Predictors of caregiver mental health difficulties and mental wellbeing

\begin{tabular}{|c|c|c|c|c|c|c|}
\hline & \multicolumn{2}{|l|}{ GHQ-12 caseness } & \multicolumn{4}{|c|}{ WEMWBS total score } \\
\hline & OR $[95 \% \mathrm{CI}]$ & $p^{*}$ & $\mathrm{~B}$ & SE B & $\beta$ & $p^{*}$ \\
\hline \multicolumn{7}{|l|}{ Child } \\
\hline Age (years) & $0.72[0.33-1.60]$ & .427 & 0.73 & 1.32 & 0.07 & .586 \\
\hline Social affect (ADOS-2 SA CSS) & $0.80[0.56-1.15]$ & .231 & -0.08 & 0.57 & -0.02 & .892 \\
\hline Restrictive and repetitive behaviour (ADOS-2 RRB CSS) & $0.72[0.48-1.07]$ & .107 & 0.57 & 0.63 & 0.11 & .367 \\
\hline Level of speech (reference category: Module 3 fluent speech) & - & - & - & - & - & \\
\hline Module 1 few/no words & $0.24[0.02-2.22]$ & .208 & -0.73 & 3.49 & -0.04 & .834 \\
\hline Module 1 some words & $0.28[0.02-4.24]$ & .358 & -2.79 & 4.47 & -0.09 & .535 \\
\hline Module 2 phrase speech & $0.96[0.14-6.57]$ & .970 & 0.02 & 3.30 & 0.00 & 0.995 \\
\hline Intellectual disability (BAS SNC < 70) & $4.71[1.02-21.77]$ & .047 & -0.67 & 2.46 & -0.04 & .787 \\
\hline Daily living skills impairment (VABS DLS SS <70) & $12.03[1.61-90.07]$ & .015 & -4.01 & 2.85 & -0.22 & .164 \\
\hline Emotional and behavioural difficulties (SDQ total: abnormal range) & $4.20[1.06-16.68]$ & .041 & $-\mathbf{5 . 4 3}$ & 2.09 & -0.32 & .012 \\
\hline \multicolumn{7}{|l|}{ Caregiver } \\
\hline Age (years) & $1.02[0.91-1.13]$ & .741 & -0.08 & 0.19 & -0.05 & .678 \\
\hline Educational level (low: NQF< < ) & $0.07[0.01-0.45]$ & .005 & 1.73 & 2.46 & 0.10 & .486 \\
\hline Income (below median) & $16.16[1.57-166.20]$ & .019 & -3.70 & 3.02 & -0.22 & .226 \\
\hline Parents living in the house (one parent) & $3.21[0.51-20.00]$ & .212 & 1.72 & 3.03 & 0.09 & .573 \\
\hline Other children with developmental disorders ( 1 or more) & $0.49[0.13-1.89]$ & .301 & 1.23 & 2.24 & 0.07 & .585 \\
\hline Group (PACT therapy) & $0.48[0.12-1.99]$ & .312 & -0.42 & 2.22 & -0.02 & .851 \\
\hline
\end{tabular}

ADOS-2 CSS, SA CSS and RRB CSS Autism Diagnostic Observation Schedule Second Edition Composite Severity Score for Total, Social Affect and Restrictive and Repetitive Behaviours, BAS SNC SS British Ability Scales Standard Nonverbal Composite Standard Score, VABS SOC SS, $V A B S$ COMM SS and VABS DLS SS Vineland Adaptive Behavior Scales Second Edition Standard Score for the Socialization, Communication and Daily Living Skills Domains, SDQ Total Strengths and Difficulties Questionnaire Total Problems Score, NQF National Qualifications Framework

*Predictors significant at $p<.05$ are marked in bold 
Confirming previous reports, the results demonstrate that raising a child with autism is associated with an increased risk for both mental health difficulties and reduced wellbeing. Thus, in our sample $48 \%$ of caregivers fell above the GHQ-12 cut-off for mental health difficulties, while $24 \%$ is the expected rate in the general population (Goldberg et al. 1997); median wellbeing levels on the WEMWBS were also significantly lower than the expected UK population median (Tennant et al. 2007; Maheswaran et al. 2012). However, when we examined the overall estimated probability of meeting 'caseness' on the GHQ-12, neither child core autism symptoms (social affect and restrictive and repetitive behaviours), nor child level of speech, were associated with caregiver mental health difficulties. We found instead that prevalence of GHQ-12 'caseness' was significantly higher in caregivers of children with ID and/or poor daily living skills and in those with elevated child emotional and behavioural difficulties. Child behavioural difficulties in autism are, across all age ranges, from toddlerhood to young adulthood, associated with parent mental health difficulties (Estes et al. 2013; Lecavalier et al. 2006; Peters-Scheffer et al. 2012) and our results replicate these findings. We also found these to be the only predictive factor for caregiver wellbeing. Low levels of wellbeing are associated with social isolation in the general population (Kinderman et al. 2015), and it possible that child behaviour difficulties lead to greater isolation and impact on caregivers' overall functioning, over and above other child and family factors. Moreover, child emotional and behavioural difficulties was the only factor associated with both mental health difficulties and reduced wellbeing, which is notable because the GHQ-12 and the WEMWBS were strongly correlated. While the concurrence may be partly attributable to rater effects as the same caregiver completed both questionnaires at the same point in time, the different patterns of association with the potential risk factors may reflect the fact that in at-risk populations the two constructs may de facto overlap more than in the general population, representing commonly co-occurring outcomes with different determinants. This point is exemplified by the WHO definition where mental health is equated to a state of well-being when the individual cope[s] with the normal stresses of life (Italics added; Herrman et al. 2005, p. XVIII).

The pattern of findings also indicates that neither parental mental health nor psychological wellbeing are directly affected by the severity of autism per se. Thus, while some studies comparing caregivers of children with ASD or other developmental disorders have suggested a disorder-specific effect, others find that group differences in parental outcomes are confounded by differences in child comorbidities or characteristics, rather than being related to core diagnostic criteria (Griffith et al. 2010; Hartley et al. 2012). Similar effects have been shown for caregivers of children with developmental delay, where higher stress was attributable to the extent of behaviour problems rather than to the presence of the developmental delay itself (Baker et al. 2003). The evidence on the effect of cognitive impairment on parental outcomes in caregivers of children with autism is inconclusive. In our sample, where the majority of children had IQ $\leq 70$ (while the estimated rate of co-occurrence is $31 \%$, CDC 2014), ID was significantly associated with GHQ-12 caseness. Our finding of poor child daily living skills predicting mental health difficulties, over and above the effect of ID, adds to the existing mixed evidence (Estes et al. 2013; Green and Carter 2014) and may be due to the age of the children in our sample. As previously suggested (Estes et al. 2013), it may be easier for caregivers to compensate for poor daily living skills when children are younger, because they are physically more manageable and the gap with peers is not as wide as in mid-childhood (Fisch et al. 2002; Gabriels et al. 2007), particularly in children with co-occurring ID (Hill et al. 2015).

Although partner support (Ekas et al. 2010) and having several children with disabilities in the family (Orsmond et al. 2007) have been found to be correlates of psychological outcomes in other studies, we did not find presence of another carer or number of other children with developmental difficulties to be predictive. Above and beyond the effect of child characteristics, the odds of caregivers reporting mental health difficulties were significantly increased by low household income, but decreased by low educational level, although the magnitude of the effect was more limited for the latter. Our results align with previous reports of adversity as a risk factor; however it should be noted that the association between socio-economic status and GHQ-12 'caseness' is inconsistent (Laaksonen et al. 2007). In the WHO study, the GHQ-12 was not influenced by educational level per se (Goldberg et al. 1997), but in our study, over and above the effect of other variables, parents with low educational level were slightly less likely to meet 'caseness' for mental health difficulties. This may reflect multiple factors, such as under-reporting of symptoms in caregivers with low educational level due to difficulties in verbal comprehension, as highlighted by Kessler and Üstün (2004) or other contextual factors associated with work commitments in highly educated caregivers (Parkes et al. 2015). Finally, it is worth mentioning that pre-school assignment to PACT intervention was not associated with rates of parental mental health difficulties or mental wellbeing levels when the children were in middle childhood. The PACT trial, which did not include parental psychological outcomes, has been shown to have lasting treatment effects on increased child initiations and in reduced severity of autism symptoms (Pickles et al. 2016) as well as on positive family life experience, as measured by the Autism Family Experience Questionnaire (AFEQ) (Leadbitter et al. in press). However in this study we did not 
find a protective effect of PACT over and above the effect of all the other risk factors, suggesting that the benefits have not carried over into more general amelioration of stresses upon caregivers of autistic children six years later. Other autism intervention trials, such as Kasari et al. (2015) and Estes et al. (2014), have reported positive effects on parenting stress, but with a much shorter follow-up periods and with a specific focus on parenting stress, rather than general mental health and wellbeing. Further research could inform whether such short-term intervention-related reductions in parental stress are sustained over the longer term and linked to overall mental health and wellbeing.

The study was limited by the lack of baseline measurement for mental health and mental wellbeing, which prevented the analysis of longitudinal associations. Additionally, there are several potential risk factors (such as negative life events, family conflict, medical illness) and protective factors (such as social support, adaptive coping strategies, self-efficacy) for poor mental health and mental wellbeing (WHO 2012) that were not measured and might have added to the predictive strength of the study. The moderate sample size required us to exclude from the analysis further subsidiary predictor variables, such as ethnicity, that may be associated with mental health status. Finally, for ease of interpretation, we opted for the ADOS Module classification as a measure of functional language in a sample where the majority of children had basal scores on formal language tests; this precluded a more fine-grained analysis of language impairment as a predictor variable. Strengths include the rigorous characterization of the sample and the combination of measures for parental psychological outcomes.

Regardless of the different possible causal pathways, sufficient evidence has accumulated to recommend specifically targeting mental health difficulties and low mental wellbeing in caregivers of children with autism. This may require service providers to include a direct focus on caregivers, such as providing advice on parenting skills, offering emotional and practical support, and opportunities for respite or psychological counselling. In the Bromley et al. study (2004), for example, almost all mothers reported a need for more help in the following areas: breaks from child-care (particularly during the holidays); doing things the parent enjoys; and advice on the best ways to help their child. There is also a need to address the child's functional abilities in the home, and their emotional and behaviour problems, since effective intervention strategies in these areas are available in children with autism (Scahill et al. 2016; Postorino et al. 2017). There is also evidence that such programmes have a positive impact on parental mental health (Tonge et al. 2006). Addressing these essential unmet needs within comprehensive intervention models could substantially improve parental psychological outcomes which, in turn, may further reduce child behaviour problems (Totsika et al. 2013).
Acknowledgments We are very grateful for the enormous contributions the PACT families have made towards this study. We also wish to thank the PACT Consortium (Rachel Cole-Fletcher, Isobel Gammer, Jessica Maxwell, Hannah Tobin, George Vamvakas). The study was supported by Medical Research Council (Grant Nos. MR/K005863/1 and G0401546).

Collaborators for the The PАCT Consortium Rachel Cole-Fletcher (Newcastle University, Newcastle, UK); Isobel Gammer (Canterbury Christ Church University, Canterbury, UK); Jessica Maxwell (Newcastle University, Newcastle, UK); Hannah Tobin (South London and Maudsley NHS Foundation Trust, London, UK) and George Vamvakas (Institute of Psychiatry, Psychology \& Neuroscience, King's College London, UK).

Author Contributions CA, BB, SB, TC, PH, JG, ALC, KL, HM, JP, AP, ES, VS conceived and designed the study. JG led the PACT trial and follow-up studies. JG, TC, ALC, and HM led the research teams at each study site. KL, ES, RC-F, HT, IG, JM, ALC, VS and CA traced and recruited the study participants, collected and coded data. ES analysed the data and led the interpretation and writing of the paper with input from all authors.

\section{Compliance with Ethical Standards}

Conflict of interest The authors declare that they have no conflict of interest.

Ethical Approval All procedures performed in studies involving human participants were in accordance with the ethical standards of the institutional and/or national research committee and with the 1964 Helsinki declaration and its later amendments or comparable ethical standards.

Informed Consent Informed consent was obtained from all individual participants included in the study.

Open Access This article is distributed under the terms of the Creative Commons Attribution 4.0 International License (http://creativecommons.org/licenses/by/4.0/), which permits unrestricted use, distribution, and reproduction in any medium, provided you give appropriate credit to the original author(s) and the source, provide a link to the Creative Commons license, and indicate if changes were made.

\section{References}

Abbeduto, L., Seltzer, M. M., Shattuck, P., Krauss, M. W., Orsmond, G., \& Murphy, M. M. (2004). Psychological well-being and coping in mothers of youths with autism, Down syndrome, or Fragile X syndrome. American Journal on Mental Retardation, 109(3), 237-254.

Aldred, C., Green, J., Howlin, P., Le Couteur, A., Slonims, V., Barron, S., et al. (2010). Supplement to. Green J, Charman T, McConachie $\mathrm{H}$, et al. Parent-mediated communication-focused treatment in children with autism (PACT): A randomised controlled trial. Lancet. https://doi.org/10.1016/S0140-6736(10)60587-9.

Baker, B. L., McIntyre, L., Blacher, J., Crnic, K., Edelbrock, C., \& Low, C. (2003). Pre-school children with and without developmental delay: Behaviour problems and parenting stress over time. Journal of Intellectual Disability Research, 47(4-5), 217-230.

Baker-Ericzén, M. J., Brookman-Frazee, L., \& Stahmer, A. (2005). Stress levels and adaptability in parents of toddlers with and 
without autism spectrum disorders. Research and Practice for Persons with Severe Disabilities, 30(4), 194-204.

Benson, P. R. (2006). The impact of child symptom severity on depressed mood among parents of children with ASD: The mediating role of stress proliferation. Journal of Autism and Developmental Disorders, 36(5), 685-695.

Bromley, J., Hare, D. J., Davison, K., \& Emerson, E. (2004). Mothers supporting children with autistic spectrum disorders. Autism: The International Journal of Research and Practice, 8(4), 409-423. https://doi.org/10.1177/1362361304047224.

CDC (2014). Developmental, Disabilities Monitoring Network Surveillance Year Principal Investigators. Prevalence of autism spectrum disorder among children aged 8 years-autism and developmental disabilities monitoring network, 11 sites, United States, 2010. Morbidity and mortality weekly report. Surveillance Summaries (Washington, DC: 2002), 63(2), 1.

Cohrs, A. C., \& Leslie, D. L. (2017). Depression in parents of children diagnosed with autism spectrum disorder: A claims-based analysis. Journal of Autism and Developmental Disorders, 47(5), $1416-1422$.

Dunn, M. E., Burbine, T., Bowers, C. A., \& Tantleff-Dunn, S. (2001). Moderators of stress in parents of children with autism. Community Mental Health Journal, 37(1), 39-52.

Ekas, N. V., Lickenbrock, D. M., \& Whitman, T. L. (2010). Optimism, social support, and well-being in mothers of children with autism spectrum disorder. Journal of Autism and Developmental Disorders, 40(10), 1274-1284.

Elliott, C., \& Smith, P. (2011). British ability scale third edition. London: GL Assessment.

Estes, A., Munson, J., Dawson, G., Koehler, E., Zhou, X. H., \& Abbott, R. (2009). Parenting stress and psychological functioning among mothers of preschool children with autism and developmental delay. [Comparative Study Research Support, N.I.H., Extramural]. Autism: The International Journal of Research and Practice, 13(4), 375-387. https://doi.org/10.1177/1362361309105658.

Estes, A., Olson, E., Sullivan, K., Greenson, J., Winter, J., Dawson, G., et al. (2013). Parenting-related stress and psychological distress in mothers of toddlers with autism spectrum disorders. Brain Developement, 35(2), 133-138.

Estes, A., Vismara, L., Mercado, C., Fitzpatrick, A., Elder, L., Greenson, J., et al. (2014). The impact of parent-delivered intervention on parents of very young children with autism. Journal of Autism and Developmental Disorders, 44(2), 353-365.

Feldman, M., McDonald, L., Serbin, L., Stack, D., Secco, M. L., \& Yu, C. (2007). Predictors of depressive symptoms in primary caregivers of young children with or at risk for developmental delay. Journal of Intellectual Disability Research, 51(8), 606-619.

Fisch, G. S., Simensen, R. J., \& Schroer, R. (2002). Longitudinal changes in cognitive and adaptive behavior scores in children and adolescents with the Fragile X mutation or autism. Journal of Autism and Developmental Disorders, 32(2), 107-114.

Gabriels, R. L., Ivers, B. J., Hill, D. E., Agnew, J. A., \& McNeill, J. (2007). Stability of adaptive behaviors in middle-school children with autism spectrum disorders. Research in Autism Spectrum Disorders, 1(4), 291-303. https://doi.org/10.1016/j. rasd.2006.11.004.

Goldberg, D. (1992). General health questionnaire (GHQ-12). Windsor: Nfer-Nelson.

Goldberg, D., Gater, R., Sartorius, N., Ustun, T. B., Piccinelli, M., Gureje, O., et al. (1997). The validity of two versions of the GHQ in the WHO study of mental illness in general health care. Psychological Medicine, 27(01), 191-197.

Goodman, R. (1997). The strengths and difficulties questionnaire: A research note. Journal of Child Psychology and Psychiatry, 38(5), 581-586. https://doi.org/10.1111/j.1469-7610.1997.tb01545.x.
Green, S. A. \& Carter, A. S. (2014). Predictors and course of daily living skills development in toddlers with autism spectrum disorders. Journal of Autism and Developmental Disorders, 44(2), 256-263. https://doi.org/10.1007/s10803-011-1275-0.

Green, Charman, T., McConachie, H., Aldred, C., Slonims, V., Howlin, P., et al. (2010). Parent-mediated communication-focused treatment in children with autism (PACT): A randomised controlled trial. Lancet, 375(9732), 2152-2160. https://doi.org/10.1016/ S0140-6736(10)60587-9.

Griffith, G. M., Hastings, R. P., Nash, S., \& Hill, C. (2010). Using matched groups to explore child behavior problems and maternal well-being in children with Down syndrome and autism. Journal of Autism and Developmental Disorders, 40(5), 610-619.

Hall, H. R., \& Graff, J. C. (2011). The relationships among adaptive behaviors of children with autism, family support, parenting stress, and coping. Issues in Comprehensive Pediatric Nursing, 34(1), 4-25. https://doi.org/10.3109/01460862.2011.555270.

Hartley, S. L., Seltzer, M. M., Head, L., \& Abbeduto, L. (2012). Psychological well-being in fathers of adolescents and young adults with Down syndrome, Fragile $\mathrm{X}$ syndrome, and autism. Family Relations, 61(2), 327-342. https://doi. org/10.1111/j.1741-3729.2011.00693.x.

Hastings, R. P., \& Johnson, E. (2001). Stress in UK families conducting intensive home-based behavioral intervention for their young child with autism. Journal of Autism and Developmental Disorders, 31(3), 327-336.

Hastings, R. P., Kovshoff, H., Ward, N. J., Degli Espinosa, F., Brown, T., \& Remington, B. (2005). Systems analysis of stress and positive perceptions in mothers and fathers of pre-school children with autism. Journal of Autism and Developmental Disorders, $35(5), 635$.

Hayes, S. A., \& Watson, S. L. (2013). The impact of parenting stress: A meta-analysis of studies comparing the experience of parenting stress in parents of children with and without autism spectrum disorder. Journal of Autism and Developmental Disorders, 43(3), 629-642.

Herrman, H., Saxena, S., \& Moodie, R. \& World Health Organization (2005). Promoting mental health: Concepts, emerging evidence, practice: A report of the World Health Organization. Department of Mental Health and Substance Abuse in collaboration with the Victorian Health Promotion Foundation and the University of Melbourne.

Hill, T. L., Gray, S. A. O., Kamps, J. L., \& Varela, Enrique, R (2015). Age and adaptive functioning in children and adolescents with ASD: The effects of intellectual functioning and ASD symptom severity. Journal of Autism and Developmental Disorders, 45(12), 4074-4083. https://doi.org/10.1007/ s10803-015-2522-6.

Hus, V., Gotham, K., \& Lord, C. (2014). Standardizing ADOS domain scores: Separating severity of social affect and restricted and repetitive behaviors. Journal of Autism and Developmental Disorders, 44(10), 2400-2412.

Jones, A. M., \& Nicolás, A. L. (2004). Measurement and explanation of socioeconomic inequality in health with longitudinal data. Health Economics, 13(10), 1015-1030.

Kasari, C., Gulsrud, A., Paparella, T., Hellemann, G., \& Berry, K. (2015). Randomized comparative efficacy study of parent-mediated interventions for toddlers with autism. Journal of Consulting and Clinical Psychology, 83(3), 554.

Kessler, R. C., \& Üstün, T. B. (2004). The World Mental Health (WMH) Survey Initiative version of the. World Health Organization (WHO) Composite International Diagnostic Interview (CIDI). International Journal of Methods in Psychiatric Research, 13(2), 93-121, https://doi.org/10.1002/mpr.168.

Kinderman, P., Tai, S., Pontin, E., Schwannauer, M., Jarman, I., \& Lisboa, P. (2015). Causal and mediating factors for anxiety, 
depression and well-being. The British Journal of Psychiatry, 206(6), 456-460. https://doi.org/10.1192/bjp.bp.114.147553.

Laaksonen, E., Martikainen, P., Lahelma, E., Lallukka, T., Rahkonen, O., Head, J., et al. (2007). Socioeconomic circumstances and common mental disorders among Finnish and British public sector employees: Evidence from the Helsinki Health Study and the Whitehall II Study. International Journal of Epidemiology, 36(4), 776-786.

Leadbitter, K., Aldred, C., McConachie, H., LeCouteur, A., Kapadia, D., Charman, T., et al. (2017). The Autism Family Experience Questionnaire (AFEQ): An ecologically-valid, parent nominated measure of family experience, quality of life and prioritised outcomes for early intervention. Journal of Autism and Developmental Disorders. https://doi.org/10.1007/s10803-017-3350-7.

Lecavalier, L., Leone, S., \& Wiltz, J. (2006). The impact of behaviour problems on caregiver stress in young people with autism spectrum disorders. Journal of Intellectual Disability Research, $50(3), 172-183$.

Lord, C., Rutter, M., DiLavore, P. C., Risi, S., Gotham, K., \& Bishop, S. (2012). Autism diagnostic observation schedule, second edition (ADOS-2). Torrance, CA: Western Psychological Services.

Maheswaran, H., Weich, S., Powell, J., \& Stewart-Brown, S. (2012). Evaluating the responsiveness of the Warwick Edinburgh Mental Well-Being Scale (WEMWBS): Group and individual level analysis. Health and Quality of Life Outcomes, 10(1), 156. doi:https:// doi.org/10.1186/1477-7525-10-156.

McStay, R. L., Dissanayake, C., Scheeren, A., Koot, H. M., \& Begeer, S. (2014). Parenting stress and autism: The role of age, autism severity, quality of life and problem behaviour of children and adolescents with autism. Autism: The International Journal of Research and Practice, 18(5), 502-510.

Olsson, M. B., \& Hwang, C. (2001). Depression in mothers and fathers of children with intellectual disability. Journal of Intellectual Disability Research, 45(6), 535-543.

ONS (2016). Statistical bulletin: Household disposable income and inequality in the UK: financial year ending 2015. In Office for National Statistics (Ed.), https://www.ons.gov.uk/peoplepopulationandcommunity/personalandhouseholdfinances/incomeandwealth/bulletins/householddisposableincomeandinequality/ financialyearending2015. UK: Office for National Statistics.

Orr, R. R., Cameron, S. J., Dobson, L. A., \& Day, D. M. (1993). Agerelated changes in stress experienced by families with a child who has developmental delays. Mental Retardation, 31(3), 171.

Orsmond, G. I., Lin, L.-Y., Seltzer, M. M., \& Taylor, S. J. (2007). Mothers of adolescents and adults with autism: Parenting multiple children with disabilities. Intellectual and Developmental Disabilities, 45(4), 257-270.

Parkes, A., Sweeting, H., \& Wight, D. (2015). Parenting stress and parent support among mothers with high and low education. Journal of Family Psychology, 29(6), 907.

Peters-Scheffer, N., Didden, R., \& Korzilius, H. (2012). Maternal stress predicted by characteristics of children with autism spectrum disorder and intellectual disability. Research in Autism Spectrum Disorders, 6(2), 696-706. https://doi.org/10.1016/j.rasd.2011.10.003.

Pickles, A., Le Couteur, A., Leadbitter, K., Salomone, E., ColeFletcher, R., Tobin, H., et al. (2016). Parent-mediated social communication therapy for young children with autism (PACT): Long-term follow-up of a randomised controlled trial. Lancet, 388(10059), 2501-2509.

Postorino, V., Sharp, W. G., McCracken, C. E., Bearss, K., Burrell, T. L., Evans, A. N., et al. (2017). A systematic review and metaanalysis of parent training for disruptive behavior in children with autism spectrum disorder. Clinical Child and Family Psychology Review, 20, 1-12.

Ragland, D. R. (1992). Dichotomizing continuous outcome variables: Dependence of the magnitude of association and statistical power on the cutpoint. Epidemiology (Cambridge, Mass.), 3(5), 434-440.

Rivard, M., Terroux, A., Parent-Boursier, C., \& Mercier, C. (2014). Determinants of stress in parents of children with autism spectrum disorders. Journal of Autism and Developmental Disorders, 44(7), 1609-1620. https://doi.org/10.1007/s10803-013-2028-z.

Salomone, E., Kutlu, B., Derbyshire, K., McCloy, C., Hastings, R. P., Howlin, P., et al. (2014). Emotional and behavioural problems in children and young people with autism spectrum disorder in specialist autism schools. Research in Autism Spectrum Disorders, $8(6), 661-668$.

Scahill, L., Bearss, K., Lecavalier, L., Smith, T., Swiezy, N., Aman, M. G., et al. (2016). Effect of parent training on adaptive behavior in children with autism spectrum disorder and disruptive behavior: Results of a randomized trial. Journal of the American Academy of Child \& Adolescent Psychiatry, 55(7), 602-609, e603.

Schieve, L. A., Boulet, S. L., Kogan, M. D., Yeargin-Allsopp, M., Boyle, C. A., Visser, S. N., et al. (2011). Parenting aggravation and autism spectrum disorders: 2007 National Survey of Children's Health. Disability and Health Journal, 4(3), 143-152.

Sparrow, S. (2005). Vineland adaptive behavior scales: Survey forms manual. Bloomington, MN: Pearson, cop.

Tennant, R., Hiller, L., Fishwick, R., Platt, S., Joseph, S., Weich, S., et al. (2007). The Warwick-Edinburgh mental well-being scale (WEMWBS): development and UK validation. Health and Quality of Life Outcomes, 5(1), 63.

Tomanik, S., Harris, G. E., \& Hawkins, J. (2004). The relationship between behaviours exhibited by children with autism and maternal stress. Journal of Intellectual and Developmental Disability, 29(1), 16-26.

Tonge, B., Brereton, A., Kiomall, M., Mackinnon, A., King, N., \& Rinehart, N. (2006). Effects on parental mental health of an education and skills training program for parents of young children with autism: A randomized controlled trial. Journal of the American Academy of Child \& Adolescent Psychiatry, 45(5), 561-569. https://doi.org/10.1097/01.chi.0000205701.48324.26.

Totsika, V., Hastings, R. P., Emerson, E., Lancaster, G. A., Berridge, D. M., \& Vagenas, D. (2013). Is there a bidirectional relationship between maternal well-being and child behavior problems in autism spectrum disorders? Longitudinal analysis of a population-defined sample of young children. Autism Research, 6(3), 201-211.

WHO (2012). Risks to mental health: An overview of vulnerabilities and risk factors. Background paper by WHO Secretariat for the development of a comprehensive mental health action plan. Geneva: WHO. 